
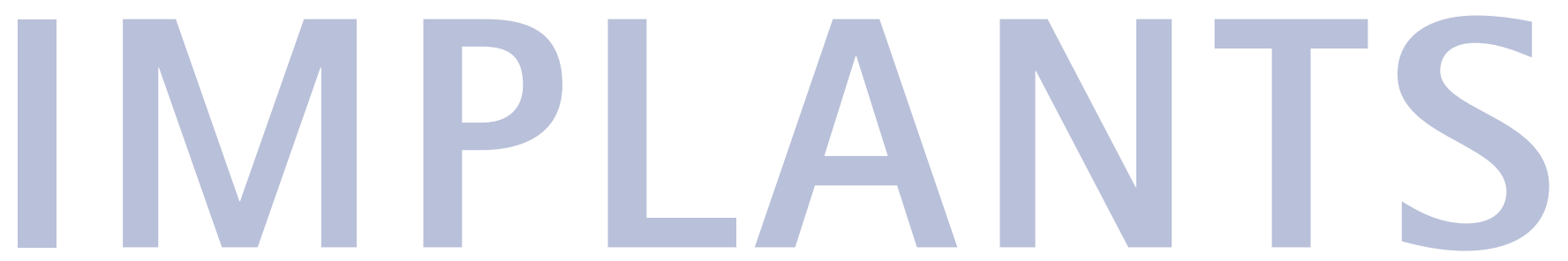

\title{
All round implant
}

According to manufacturer Dentsply Friadent the new XiVE implant offers an accelerated procedure, with multiple prosthetic options, but without the need for expensive and complicated surgical and laboratory techniques.

Through its thread design and simplified surgical procedure, it offers an implant for all types of bone.

The internal implant-abutment connection, proven in use for over ten years, is fully compatible with the prosthetic components and instruments of the Frialit-2 system.

Reader response number 55

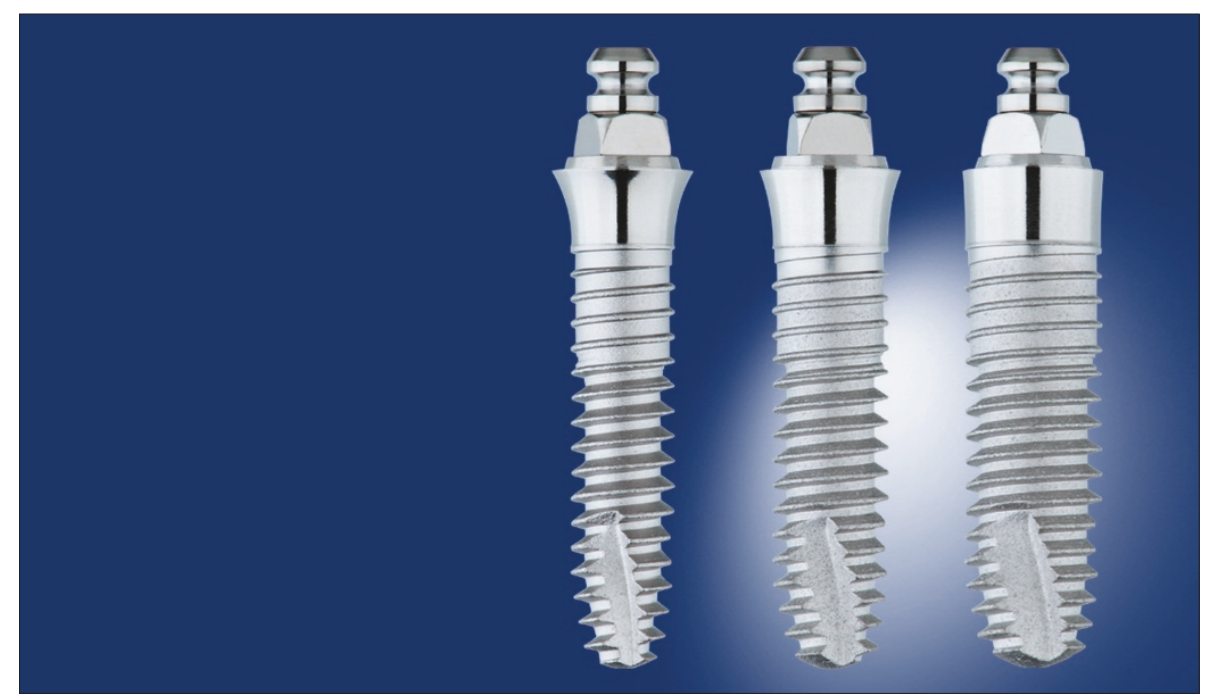




\section{Mini implants}

The New Mini Orthodontic Implant range from DB Orthodontics claims to provide absolute anchorage for orthodontic tooth movement. Manufactured in surgical stainless steel, they can be used in combination with elastic chains, elastic ligatures and preformed NiTi springs.

They are designed to induce orthodontic movements without any loss of anchorage and are easy to place as they do not osteointegrate and are also easily removed when treatment is complete.

The product is available in an introductory kit containing 24 Mini Orthodontic
Implants (2 in each of the various sizes), four site preparation drills and a screwdriver.

Reader response number 56

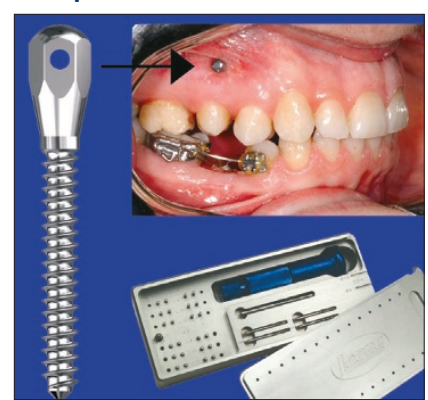

\section{Angled abutment}

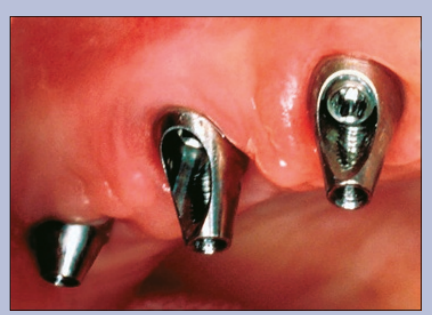

The Angled Abutment system from Astra Tech has a conical seal design which enables it to create a tight and firm connection. The indexing feature allows easy parallel placement of the abutments, promising the correct positioning during prosthetic procedures. The system is made up of a series of components including an abutment, an abutment screw in pure grade 4 titanium, and prosthetic and laboratory components.

Reader response number 57

\section{Seeing clearly}

The 0P100 with Ortho Trans linear tomography for cross sectional imaging can be used for successful site planning according to Minerva Dental. The OP100 film based panoramic unit employs special imaging geometry that enables direct comparisons to be made between case studies where appropriate.

It features the latest HF generator technology to improve the radiation efficiency and a patented v-shaped x-ray beam that adapts to the bone density and structure of the human anatomy.

Reader response number 58

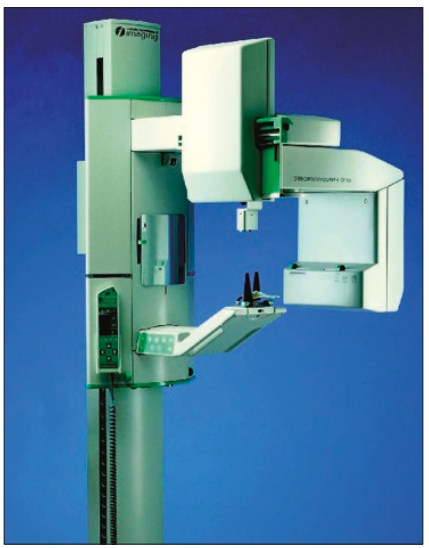




\section{New generation implants}

TRI Mini-transitional Implants from Haley have many indications, including the provision of temporary bridges for the restoration of edentulous ridges, supporting immediate dentures after implant surgery and stabilising dentures in cases with a narrow ridge. The range is divided into transitional and long-term implants, each of which features a $2.4 \mathrm{~mm}$ diameter thread and $3 \mathrm{~mm}$ smooth trans-gingival section.

The long-term implants also feature an integrated surface for additional retention, which is signified by their additional SR coding. The surgical components of the system comprise a $2 \mathrm{~mm}$ internal irrigation drill, for preparing the location site, an insertion tool for a hex ratchet, an inser-

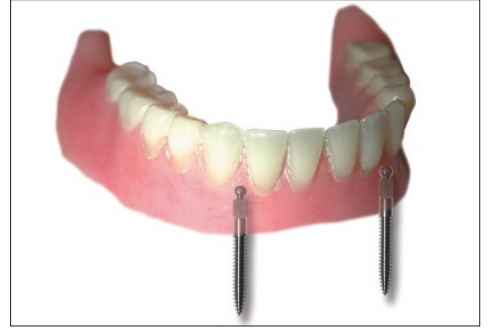

tion tool for a square ratchet and a hex ratchet.

The prosthetic components of the system include a nylon coping for crown restorations or impression transfer techniques, a nylon cap, and an analog for the TRI implants.

Reader response number 59

\section{Non-scratch instruments}

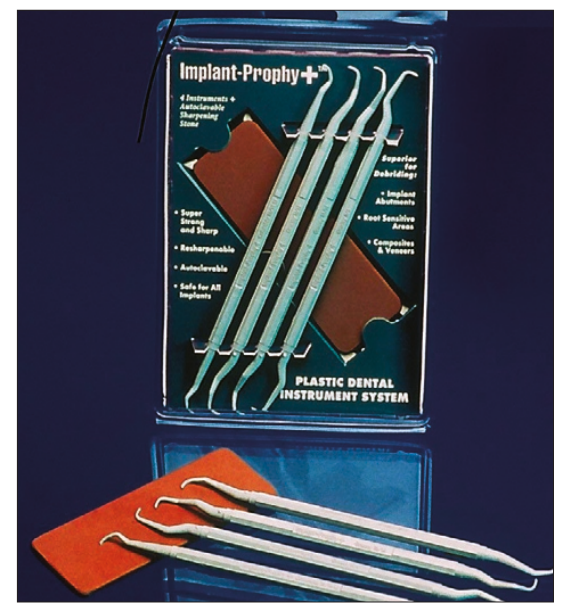

Oraldent has just launched the ImplantProphy+ Implant Scaling System which feel and function like standard steel instruments but will not scratch implant abutments. Unlike other implant scalers, the Implant-Prophy+ instruments can be resharpened many times using the synthetic abrasive sharpening stone included in the kit and the instruments can be autoclaved 80-100 cycles with no effect on performance.

The product can be used for debridement of implant abutments or sensitive root surfaces without marring composite or ceramic restorations.

Reader response number 60

\section{Multi-functional microsaw}

Nouvag Microsaws from Haley provide an atraumatic method for preparing bone blocks and harvesting intra-oral bone. They can also be used for the creation of access windows for surgical procedures including root resections, cystectomies, removal of foreign bodies or deep fractured roots, displaced and retained teeth, transposition of the inferior alveolar neurovascular bundle and bone splitting.

They are available in a variety of presentations including the Micro Compass Saw and Micro Oscillating Saw. Supplied with an E-Type fitting and external irrigation the Micro Compass Saw delivers 150 oscillations per second at $15000 \mathrm{rpm}$. With a stroke height of $2.5 \mathrm{~mm}$ it is designed for use with Nouvag saw blades. $0.4 \mathrm{~mm}$ thick, the latter are supplied as $10 \mathrm{~mm}, 15 \mathrm{~mm}$, $17 \mathrm{~mm}, 21 \mathrm{~mm}$ and $25 \mathrm{~mm}$ straight blades in packs of 6 .

The Micro Oscillating Saw also has an E-Type coupling and external irrigation. With a recommended maximum speed of
12000 rpm (equivalent to 12000 oscillations per minute) it also has a stroke height of $2.5 \mathrm{~mm}$. It is designed for use with $0.4 \mathrm{~mm}$ Oscillating Saw Blades, which are available in $7 \mathrm{~mm}, 11 \mathrm{~mm}$ and $16 \mathrm{~mm}$ blade widths on either long or short shanks.

Reader response number 61

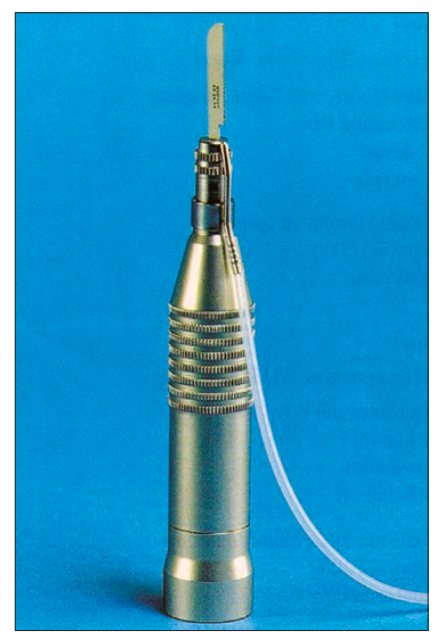

